\title{
Removal of Pigments from Palm Oil Using Activated Ibusa Kaolinite: Equilibrium, Kinetic and Thermodynamic Studies
}

\author{
Vincent Nwoye Okafor ${ }^{1}$, Ikechukwu Abuchi Nnanwube ${ }^{2 *}$, John Ifeanyi Obibuenyi², \\ Okechukwu Dominic Onukwuli', Regina Obiageli Ajemba ${ }^{1}$ \\ ${ }^{1}$ Department of Chemical Engineering, Nnamdi Azikiwe University, Awka, Nigeria \\ ${ }^{2}$ Department of Chemical Engineering, Madonna University, Akpugo, Nigeria \\ Email: ${ }^{\star}$ ik.nnanwube@gmail.com
}

How to cite this paper: Okafor, V.N., Nnanwube, I.A., Obibuenyi, J.I., Onukwuli, O.D. and Ajemba, R.O. (2019) Removal of Pigments from Palm Oil Using Activated Ibusa Kaolinite: Equilibrium, Kinetic and Thermodynamic Studies. Journal of Minerals and Materials Characterization and Engineering, 7, 157-170.

https://doi.org/10.4236/jmmce.2019.74012

Received: June 14, 2019

Accepted: July 20, 2019

Published: July 23, 2019

Copyright $\odot 2019$ by author(s) and Scientific Research Publishing Inc. This work is licensed under the Creative Commons Attribution International License (CC BY 4.0).

http://creativecommons.org/licenses/by/4.0/

\section{(c) (i) Open Access}

\begin{abstract}
The effectiveness of Ibusa kaolinite as an adsorbent in removing pigments from palm oil has been investigated in this study. Ibusa kaolinite was prepared as an adsorbent by treating it with hydrochloric acid. The surface area of the clay was found to increase with increase in acid dosage up to a maximum and then decreased while its cation exchange capacity decreased with increase in acid dosage. The activated clay was used as an adsorbent for the removal of pigments from palm oil. The bleaching process was investigated by varying the clay dosage, acid concentration and temperature. The highest removal of pigments was recorded at $7 \mathrm{M} \mathrm{HCl}$ concentration, $4 \mathrm{~g}$ clay dosage and $100^{\circ} \mathrm{C}$ temperature, and about $97.4 \%$ pigments were removed in $80 \mathrm{mi}$ nutes. Four isotherm models, three kinetic models, and the intra-particle diffusion model were applied to fit the experimental data. It was found that the equilibrium data were best represented by the Temkin isotherm model. The experimental data fitted well the pseudo-second-order kinetic model. Diffusion studies indicated that intra-particle diffusion is not the sole rate-controlling factor. The bleaching process was found to be spontaneous and endothermic, with increasing randomness of adsorbed species.
\end{abstract}

\section{Keywords}

Kaolinite, Bleaching, Kinetics, Palm Oil, Thermodynamics

\section{Introduction}

Kaolinite, which is a hydrated aluminium silicate with the chemical formula $\mathrm{Al}_{2} \mathrm{Si}_{2} \mathrm{O}_{5}(\mathrm{OH})_{4}$ is the most abundant true clay mineral. Raw clay material that 
consists primarily of kaolinite is called kaolin. Kaolinite occurs in nature in relatively thick beds made up of billions of these tiny kaolinite crystals, which typically measure about one micrometer, across the plate face by about 0.1 micrometer in thickness. Several structural variations of the fixed kaolinite formula exist, depending on differences in internal arrangement of the $\mathrm{Al}, \mathrm{Si}$, and $\mathrm{O}$ atoms in the crystal [1].

Vegetable oils in their crude form are deeply coloured. These colour impurities have to be removed to make the final product attractive and acceptable to the end user. Impurities in vegetable oil include pigments such as chlorophyll, tocopherol, xanthophylls, carotenoid, phosphatides, trace metals, traces of soap, peroxides and free fatty acids [2].

The impurity load in vegetable oils can be reduced considerably by bleaching which is an adsorption process that utilizes clay as adsorbent. This may be naturally active or activated clays. Naturally active clays possess some bleaching activity and show a high adsorption capacity due to their high surface area. However, activated bleaching clays show a much higher activity [3].

Adsorbents are activated by a mineral acid treatment resulting in the dealumination of the structure. A number of metal ions in the octahedral layer and impurities such as calcite are also removed by leaching with an inorganic acid at elevated temperature [4]. In addition, the edges of the platelets are opened, and, as a result of all these changes, the pore diameters and the surface area increase.

Ajemba and Onukwuli [5] carried out a study on the influence of hydrochloric acid leaching on the structural changes and bleaching performance of Udi clay. The acid-leached samples were tested in order to ascertain their performance in bleaching palm oil and it was observed that the bleaching efficiency increased from $29 \%$ to $66 \%$. Motlagh et al. [6] reported that acid activation of clay from Khorasan, Iran, increased its adsorbing ability from $6.35 \%$ to $96.4 \%$ efficiency using $5 \mathrm{~N}$ sulphuric acid.

The present study focuses on the removal of pigments from palm oil using acid activated Ibusa clay. Different adsorption isotherms and kinetic models were fitted to the experimental data. In addition, thermodynamic parameters such as $\Delta G^{o}, \Delta H^{o}$, and $\Delta S^{o}$ were estimated.

\section{Materials and Methods}

\subsection{Materials}

The kaolinite sample used in this research was sourced from Delta State of Nigeria-Ibusa (Lat 6'11"N, Long 6'38"E). At the point of mining, the clay was wet and the debris was manually separated. It was spread in the sun for 24 hours to dry. The crude palm oil (CPO) was bought from local oil mill at Ezema village, Ojoto in Idemili South local government area of Anambra State Nigeria. The crude palm oil was degummed with the use of phosphoric acid. It was then characterized with atomic absorption spectrophotometer (AAS). The picture of Ibusa kaolinite is shown in Plate 1. 


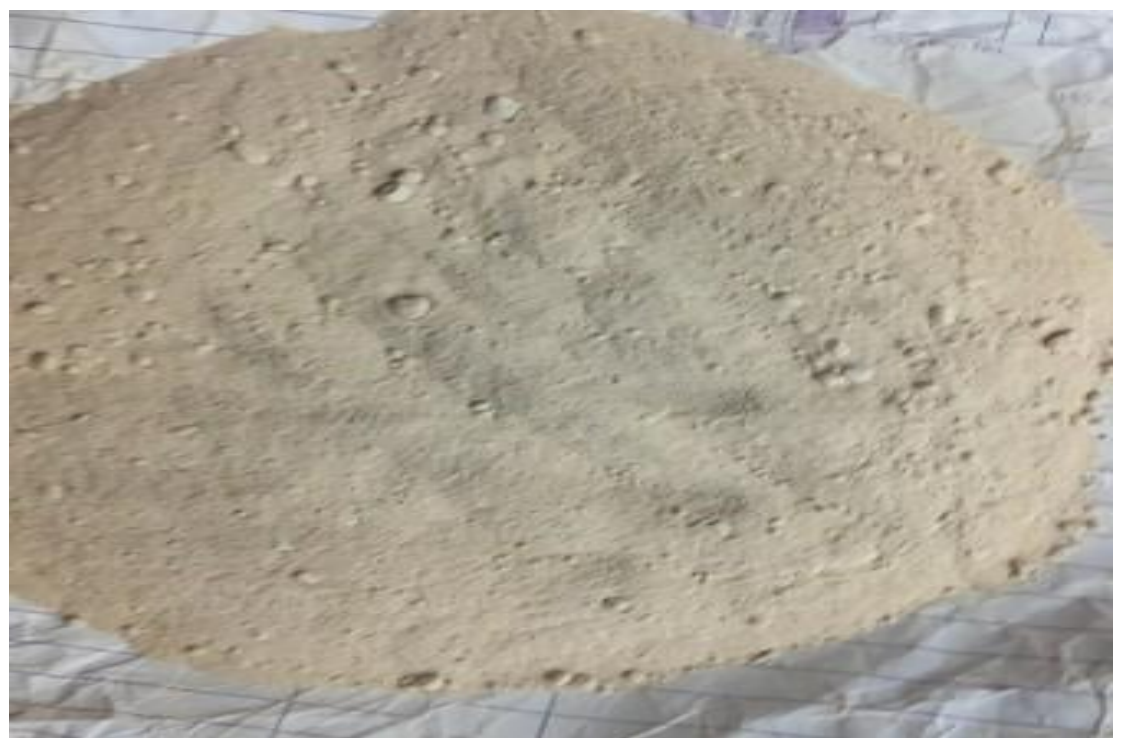

Plate 1. Ibusa kaolinite.

\subsection{Methods}

\subsubsection{Clay Preparation and Activation}

The clay material was prepared for activation by drying it under the sun at an ambient temperature of $35^{\circ} \mathrm{C}$ to make them amenable to grinding. The clay sample was then pulverized and sieved to a particle of $300 \mu \mathrm{m} .50 \mathrm{~g}$ of the clay sample was mixed with $250 \mathrm{ml}$ of the prepared acid. The resulting suspension was heated on a magnetically stirred hot plate at a temperature of $98^{\circ} \mathrm{C}$ for 2.0 hours. The clay residue was washed free of the acid several times with distilled water until a neutral point was obtained with $\mathrm{pH}$ meter. The clay was then dried at a temperature of $110^{\circ} \mathrm{C}$ for 3 hours, then ground again using laboratory mortar and pestle, sieved with $75 \mu \mathrm{m}$ sieve and stored in desiccators. Also, the effect of acid concentration on the physical properties of the clay samples was investigated by measuring the cation exchange capacity and surface area of the samples at each acid concentration used in the activation process.

\subsubsection{XRF and FTIR Analysis}

An ARL 9400XP+ Wavelength-dispersive XRF Spectrometer with a Rh source was used for the X-ray fluorescence analyses of the samples. The NBSGSC fundamental parameter program was used for matrix correction of major elements, as well as $\mathrm{Cl}, \mathrm{Co}, \mathrm{Cr}, \mathrm{V}, \mathrm{Sc}$, and $\mathrm{S}$. The $\mathrm{Rh}$ Compton peak ratio method was used for the other trace elements. Samples were dried and fired at $1000^{\circ} \mathrm{C}$ to determine the percentage loss on ignition; for the samples this was less than $2 \%$. Major element analyses were carried out on fused beads. A pre-fired sample of $1 \mathrm{~g}$ and $6 \mathrm{~g}$ of lithium tetra-borate flux was mixed in a 5\% Au/Pt crucible and fused at $1000^{\circ} \mathrm{C}$ in a muffle furnace, with occasional swirling. The glass disk was transferred into preheated $\mathrm{Pt} / \mathrm{Au}$ mould and the bottom surface was analyzed.

The infrared spectra were recorded in the mid-infrared region (400 - 4500 $\mathrm{cm}^{-1}$ ) in an evacuated chamber of Shimadzu FTIR-8400S spectrophotometer 
using potassium bromide $(\mathrm{KBr})$ discs as matrices. A spectral resolution of $2 \mathrm{~cm}^{-1}$ was used and spectra were accumulated over 32 scans. The FTIR spectroscopy was applied to all samples. Only $2 \mathrm{mg}$ of each sample was mixed with $100 \mathrm{mg}$ of $\mathrm{KBr}$ and pressed under 6 tonnes for 2 minutes in making disk. At first the samples were crushed and ground before making the $\mathrm{KBr}$ pellets. The fitting of peaks and smoothing were done with OPUS 2000 software on the Shimadzu $8400 \mathrm{~S}$ over the working window, $400-4500 \mathrm{~cm}^{-1}$.

\subsubsection{Bleaching Experiment}

$100 \mathrm{~g}$ of the refined unbleached palm oil was measured out into a $250 \mathrm{ml}$ conical flask and $2 \mathrm{~g}$ of the sized activated clay samples were also added. The mixture of clay and oil was heated to a temperature of $80^{\circ} \mathrm{C}$ for thirty minutes on a magnetically stirred hot plate. At the completion of the time, the hot oil and clay mixture was filtered under gravity using Whatman filter paper No.42 $(15 \mathrm{~cm}$ diameter), before measuring the absorbance. The bleaching/adsorption efficiency of the activated clay samples was then determined by measuring the color of the bleached oil using UV-VIS Spectrophotometer (Model WFJ 525) at $450 \mathrm{~nm}$ [5]. The bleaching efficiency is defined by the following expression in Equation (1).

$$
\text { Bleaching Efficiency }(\%)=\frac{A_{\text {unbleached }}-A_{\text {bleached }}}{A_{\text {unbleached }}} \times 100
$$

where $A_{\text {unbleached }}$ and $A_{\text {bleached }}$ are absorbencies of unbleached and bleached palm oil respectively, at $450 \mathrm{~nm}$.

To investigate the effect of process variables on bleaching efficiency of the activated clay sample, the above experimental procedure was carried out at different values of the parameters. The experiment was performed at different mass (concentration) of the adsorbent (activated clay) which was varied at 1, 2, 3, 4, and 5 grams. The temperature and time of heating were also varied at $70^{\circ} \mathrm{C}$, $80^{\circ} \mathrm{C}, 90^{\circ} \mathrm{C}$, and $100^{\circ} \mathrm{C}$ and $5,10,15,20,30,40,50,60,70$ and 80 minutes, respectively. The effect of activation parameters on the bleaching/adsorption efficiency of the clay samples was studied by using the different samples activated with varying acid concentration in the bleaching process.

\section{Results and Discussion}

\subsection{XRF Analysis}

The result of XRF analysis of the clay shows that Alumina $\left(\mathrm{Al}_{2} \mathrm{O}_{3}\right)$, Iron Oxide $\left(\mathrm{Fe}_{2} \mathrm{O}_{3}\right)$ and Silicon Oxide $\left(\mathrm{SiO}_{2}\right)$ are present in major quantities while other components are present in trace amounts. The following compositions were obtained: $\mathrm{Al}_{2} \mathrm{O}_{3}$ (17.5\%), $\mathrm{SiO}_{3}$ (56.60\%), $\mathrm{Fe}_{2} \mathrm{O}_{3}$ (19.29\%), $\mathrm{SO}_{3}$ (1.52\%), $\mathrm{CaO}$ (2.36\%), $\mathrm{TiO}_{2}$ (2.36\%), $\mathrm{V}_{2} \mathrm{O}_{5}$ (0.14\%), $\mathrm{Cr}_{2} \mathrm{O}_{3}$ (0.09\%), $\mathrm{Mn}_{2} \mathrm{O}_{3}(0.20 \%), \mathrm{P}_{2} \mathrm{O}_{5}$ (0.43\%), $\mathrm{NiO}(0.04 \%), \mathrm{CuO}(0.03 \%), \mathrm{ZnO}(0.06 \%), \mathrm{MoO}_{3}(0.30 \%), \mathrm{Rh}_{2} \mathrm{O}_{3}$ (1.10\%), $\mathrm{Ta}_{2} \mathrm{O}_{5}$ (0.10\%), $\mathrm{Re}_{2} \mathrm{O}_{7}(0.10 \%), \mathrm{IrO}_{2}(0.27 \%), \mathrm{Se}_{2} \mathrm{SO}_{3}(0.03 \%), \mathrm{CdO}$ $(0.60 \%)$. 


\subsection{FTIR Analysis}

The FTIR spectra of Ibusa clay is shown in Figure 1. The result revealed the functional groups present in the clay. The band at $524 \mathrm{~cm}^{-1}$ is attributed to $\mathrm{C}-\mathrm{C}=\mathrm{O}$ bend, $\mathrm{C}-\mathrm{Br}$ and $\mathrm{C}-\mathrm{I}$ stretches. The band at $792.77 \mathrm{~cm}^{-1}$ is attributed to $\mathrm{C}-\mathrm{Cl}$ stretch and $\mathrm{CH}$ out-of-phase deformation while the band at $1020.38 \mathrm{~cm}^{-1}$ is attributed to Si-O-Si and P-O-C anti-symmetrical stretches. The band at 1107.18 $\mathrm{cm}^{-1}$ is attributed to $\mathrm{C}-\mathrm{N}, \mathrm{C}-\mathrm{O}$ and $\mathrm{C}=\mathrm{S}$ stretches as well as $\mathrm{C}-\mathrm{O}-\mathrm{C}$ anti-symmetrical stretch while the band at $1635.65 \mathrm{~cm}^{-1}$ could be attributed to Al-O-H stretching. The band at $3399.65 \mathrm{~cm}^{-1}$ is attributed to $\mathrm{OH}$ stretch for solids and liquids as well as $\mathrm{NH}$ stretch for dilute solution.

\subsection{Physical Characterization}

The physical properties of the raw and activated clay sample used as adsorbent are given in Table 1, whereas the chemical properties of the palm oil before and after bleaching are given in Table 2. The result shows that the bulk density, $\mathrm{pH}$ and cation exchange capacity of the clay decreased upon activation, while the oil retention, surface area and acidity increased with activation.

Table 1. Physical properties of the adsorbent (activated with $\mathrm{HCl}$ ).

\begin{tabular}{ccc}
\hline Property & \multicolumn{2}{c}{ Ibusa clay } \\
\cline { 2 - 3 } & Raw & Activated \\
\hline Bulk density $\left(\mathrm{g} / \mathrm{cm}^{3}\right)$ & 954.6 & 753.9 \\
Oil retention $(\%)$ & 22 & 45 \\
Surface area $\left(\mathrm{m}^{2} / \mathrm{g}\right)$ & 72.4 & 259.2 \\
Acidity & 0.01 & 0.02 \\
$\mathrm{pH}$ & 6.6 & 4.2 \\
CEC $(\mathrm{meg} / 100 \mathrm{~g})$ & 81 & 68 \\
\hline
\end{tabular}



Figure 1. FTIR spectrum of Ibusa clay. 
Table 2. Chemical properties of the palm oil before and after bleaching.

\begin{tabular}{ccc}
\hline Property & Crude palm oil & Bleached palm oil \\
\hline Absorbance & 2.763 & - \\
Moisture content \% & 2.72 & 1.11 \\
Peroxide value (meg/kg) & 0.867 & 0.001 \\
Free fatty acid (FFA) \% & 7.473 & 8.11 \\
Deterioration of bleachability index (DOB) \% & 2.56 & 1.61 \\
Iron (ppm) & 5 & 3.1 \\
Phosphorous (ppm) & 9.2 & 5.1 \\
\hline
\end{tabular}

\subsection{Determination of the Best Activation Conditions}

The variation of the surface area and the cation exchange capacity of the adsorbent used with the level of the acid activation were closely monitored as these properties of the adsorbent play an important role in determining their adsorption/bleaching efficiency for edible oil.

\subsubsection{Effect of Acid Dosage on Cation Exchange Capacity (CEC)}

The effect of increasing the acid activation level on the cation exchange using $\mathrm{HCl}$ is shown in Figure 2. The result shows that the cation exchange capacity of the clay sample decreased with increase in the acid dosage.

\subsubsection{Effect of Acid Dosage on the Surface Area}

The effect of increasing the acid dosage during activation on the surface area is given in Figure 3. The Figure shows that the surface area increased with the increase in acid dosage, though, a maximum value was reached when the structure of the clay sample was believed to have collapsed which led to the reduction in the surface area as the acid dosage was increased further. In general, surface area increases with increase in severity of acid treatment but it does pass through a maximum beyond which additional acid treatment actually reduces the surface area [7].

\subsubsection{Effect of Acid Concentration on the Bleaching Efficiency}

Figure 4 shows the effect of acid concentration on the bleaching efficiency of the clay sample. Also, from Figure 4, it was observed that the percentage bleaching efficiency of the clay samples measured by the percentage colour reduction increased as the acid concentration increased. Though, the increase in the colour reduction approached a maximum above which the bleaching efficiency starts to drop. This could be attributed to the complete destruction of the clay structure by excess acid. A maximum concentration of $7.0 \mathrm{~mol} / \mathrm{l}$ was observed for Ibusa clay activation with percentage colour reduction of $69.5 \%$. Beyond this, further increase in concentration reduced the colour reduction ability of the clay.

\subsubsection{Effect of Clay Dosage on the Adsorption Efficiency}

Different dosages of the clay/adsorbent material were used to adsorb colour 


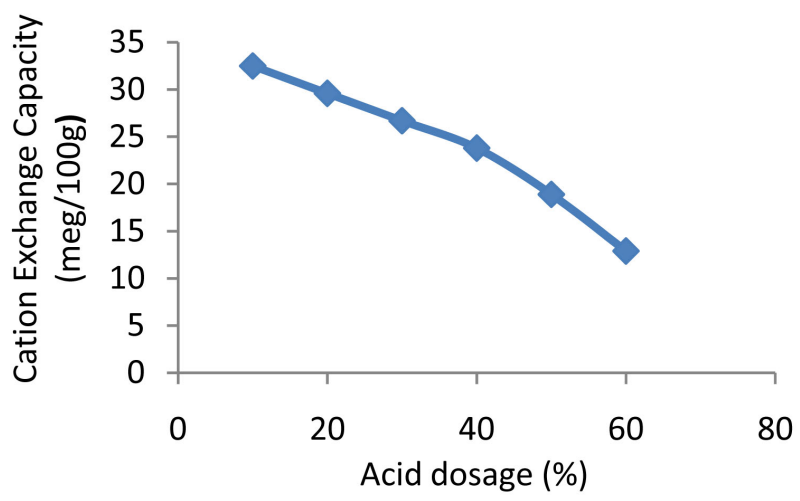

Figure 2. Effect of acid dosage on CEC of the clay sample using $\mathrm{HCl}$.

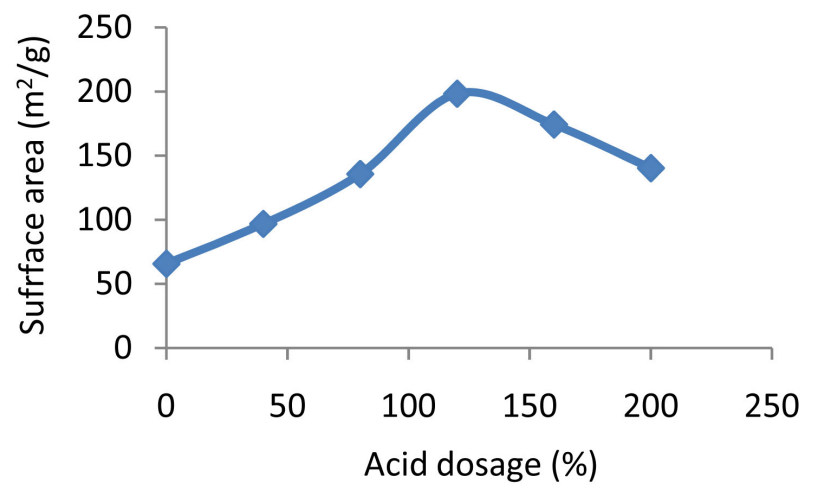

Figure 3. The effect of acid dosage on the surface area of the clay samples using $\mathrm{HCl}$.



Figure 4. Effect of the concentration of $\mathrm{HCl}$ on bleaching efficiency of Ibusa clay.

pigments from degummed palm oil. The relationships between the percentage colour reduction and the clay dosage variation using the clay sample is shown in Figure 5, when hydrochloric $(\mathrm{HCl})$ was used for activation. It was observed that as the clay dosage increased, the colour reduction efficiency increased; though this increase in colour reduction efficiency decreased in rate as the clay dosage was increased beyond a certain dose. This could be attributed to the fact that as adsorption progresses, the active sites available in the clay particles are being occupied by adsorbed particles which block further adsorption, thereby reducing the rate at which colour pigments are removed from the oil [8], [9]. 


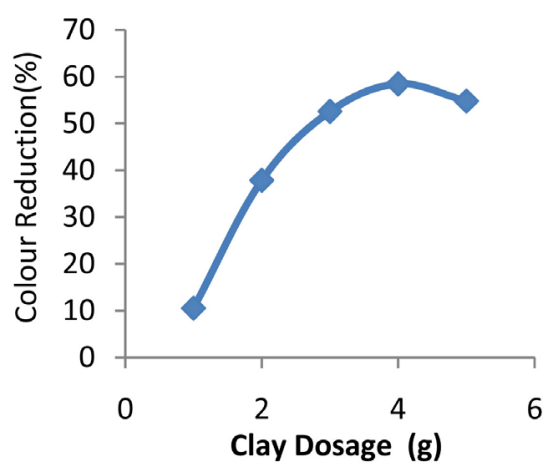

Figure 5. Plot of percentage colour reduction against clay dosage for Ibusa clay using $\mathrm{HCl}$.

\subsubsection{Effect of Temperature on the Adsorption Efficiency}

Figure 6 shows the effect of varying the temperature of adsorption from $70^{\circ} \mathrm{C}$ to $100^{\circ} \mathrm{C}$ on the adsorption efficiency of the adsorbent prepared from Ibusa clay with hydrochloric acid. The result shows that the amount of colour pigments adsorbed by the activated clay samples increased as the temperature increased up to $100^{\circ} \mathrm{C}$.

\subsection{Kinetics of Bleaching}

The influence of temperature on the bleaching efficiency of Ibusa clay activated with $7 \mathrm{M}$ hydrochloric acid has been shown in Figure 6. The result shows that the time to reach equilibrium was more than 60 minutes at all temperatures. The experimental data shown in Figure 6 was analyzed using known kinetic models in order to investigate the kinetics of the adsorption process. The kinetic models used in the analysis of the data are as follows: Pseudo-first order [10], Pseudo-second order [10], Elovich [11], and Intra-particle diffusion [11]. The respective linear forms of the equations are as given in Equations (2)-(5).

$$
\begin{aligned}
\log \left(q_{e}-q_{t}\right) & =\log q_{e}-\frac{k_{1}}{2.303} t \quad \text { (Pseudo-first-order model) } \\
\frac{t}{q_{t}} & =\frac{1}{k_{2} q_{e}^{2}}+\frac{t}{q_{e}} \quad \text { (Pseudo-second-order model) } \\
q_{t} & =\frac{1}{\beta} \ln (a \beta)+\frac{1}{\beta} \ln t \quad \text { (Elovich model) } \\
q_{t} & =K_{i d} t^{\frac{1}{2}}+c \quad \text { (Intra-particle diffusion model) }
\end{aligned}
$$

The associated kinetic parameters have been evaluated from the slopes and intercepts of the respective linear plots of the kinetic equations, and the values are shown in Table 3.

Comparison of the analyzed data based on the linear regression coefficient $\left(R^{2}\right)$ values as shown in Table 3 for the different kinetic model equations showed that the experimental data is best described by the pseudo-second order equation (Equation (3)), which has the most linear fit with average correlation coefficient $\left(R^{2}\right)>0.998$. Hence, the plot of the linear form of the pseudo-second order 


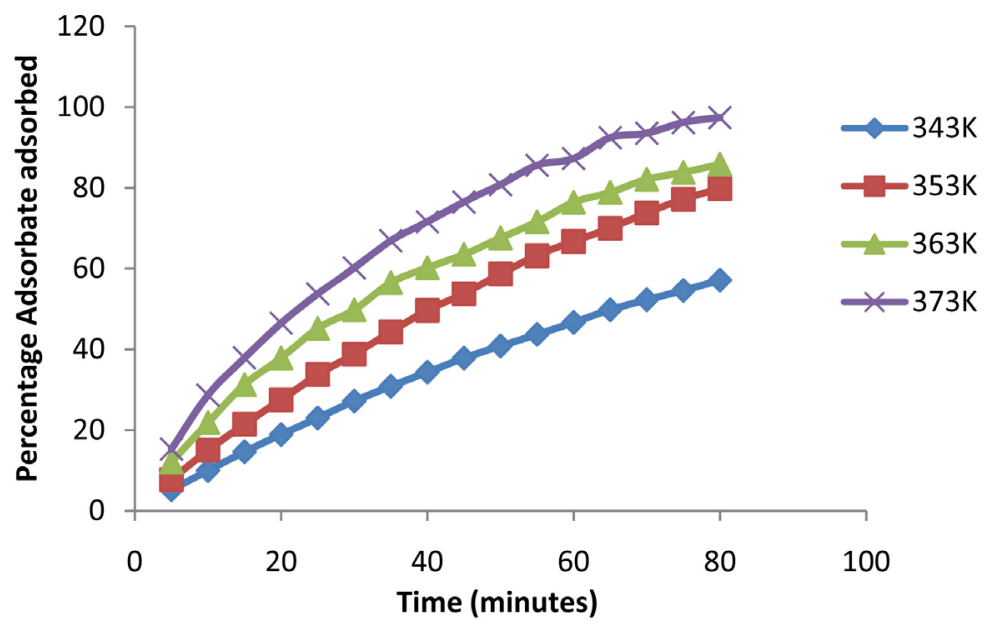

Figure 6. Effect of temperature on the percentage adsorbate adsorbed using Ibusa clay activated with $\mathrm{HCl}$.

Table 3. Adsorption kinetic parameters evaluated from the kinetic models at different temperatures.

\begin{tabular}{cccccc}
\hline \multirow{2}{*}{ Kinetic models } & Parameters & \multicolumn{4}{c}{ Temperature $(\mathrm{K})$} \\
\cline { 3 - 6 } & & 343 & 353 & 363 & 373 \\
\hline \multirow{2}{*}{ Pseudo-first-order } & $K_{1}\left(\mathrm{~min}^{-1}\right)$ & $3.22 \times 10^{-2}$ & $3.22 \times 10^{-2}$ & $3.92 \times 10^{-2}$ & $4.15 \times 10^{-2}$ \\
& $q_{e}(\mathrm{mg} / \mathrm{g})$ & 0.701 & 0.986 & 1.183 & 1.040 \\
& $R^{2}$ & 0.947 & 0.950 & 0.947 & 0.959 \\
Pseudo-second-order & $K_{2}(\mathrm{~g} / \mathrm{mg} \cdot \mathrm{min})$ & $3.59 \times 10^{-3}$ & $3.41 \times 10^{-3}$ & $1.19 \times 10^{-2}$ & $1.40 \times 10^{-2}$ \\
& $q_{e}(\mathrm{mg} / \mathrm{g})$ & 1.727 & 2.165 & 1.473 & 1.550 \\
& $R^{2}$ & 0.998 & 0.997 & 0.997 & 0.998 \\
Elovich & $A(\mathrm{mg} / \mathrm{g} \cdot \mathrm{min})$ & $3.21 \times 10^{-2}$ & $4.69 \times 10^{-2}$ & $6.33 \times 10^{-2}$ & $7.87 \times 10^{-2}$ \\
& $B(\mathrm{~g} / \mathrm{mg})$ & 0.500 & 3.559 & 3.497 & 3.125 \\
& $R^{2}$ & 0.932 & 0.939 & 0.972 & 0.980 \\
& $K_{i d}\left(\mathrm{mg} / \mathrm{g} \cdot \mathrm{min}{ }^{1 / 2}\right)$ & 0.080 & 0.112 & 0.112 & 0.125 \\
Intra-particle diffusion & $c$ & -0.158 & -0.210 & -0.121 & -0.096 \\
& $R^{2}$ & 0.995 & 0.996 & 0.997 & 0.992 \\
\hline
\end{tabular}

kinetic equation is shown in Figure 7. The pseudo-second order rate constant decreased as the temperature increased from $70^{\circ} \mathrm{C}$ to $80^{\circ} \mathrm{C}$ and then increased from $80^{\circ} \mathrm{C}$ to $100^{\circ} \mathrm{C}$.

\subsection{Adsorption Isotherms}

\subsubsection{Langmuir Isotherm}

Langmuir considered adsorption to distribute molecules over the surface of the adsorbent in the form of a uni-molecular layer and for dynamic equilibrium between adsorbed and free molecules [12]. The linear form of the Langmuir isotherm model is given in Equation (6). 




Figure 7. Pseudo-second order kinetic plot for colour pigment removal from palm oil using activated Ibusa clay.

$$
\frac{C_{e}}{q_{e}}=\frac{1}{K_{a} Q_{m}}-\frac{C_{e}}{Q_{m}}
$$

where, $C_{e}$ is the equilibrium concentration of the pigment adsorbed $(\mathrm{mg} / \mathrm{L})$; $q_{e}$ is the amount of pigment adsorbed $(\mathrm{mg} / \mathrm{g}), K_{a}$ is the Langmuir adsorption constant $(\mathrm{L} / \mathrm{mg})$ and $Q_{m}$ is the theoretical maximum adsorption capacity $(\mathrm{mg} / \mathrm{g})$. Since the absorbance measurements are taken in all experiments for the bleaching process, the relative amount of pigment adsorbed $(X)$ and the residual relative amount at equilibrium $\left(X_{e}\right)$ are obtained from Equations (7) and (8).

$$
\begin{gathered}
X=\frac{A_{o}-A_{t}}{A_{o}} \\
X_{e}=\frac{A_{t}}{A_{o}}=1-X
\end{gathered}
$$

where, $A_{o}$ is the absorbance of unbleached (crude) palm oil and $A_{t}$ is the absorbance of bleached oil at time $t$. By writing $X_{e}$ instead of $C_{e}$ and $X / m$ instead of $q_{e}$, where $m$ is the mass of the adsorbent, Langmuir isotherm takes a new form as shown in Equation (9).

$$
\frac{X_{e}}{X / m}=\frac{1}{K_{a} Q_{m}}-\frac{X_{e}}{Q_{m}}
$$

\subsubsection{Freundlich Isotherm}

The Freundlich isotherm is based on the multilayer adsorption (heterogeneous surface) [13]. The linearized form of Freundlich isotherm is given in Equation (10).

$$
\ln q_{e}=\ln K_{F}+\frac{1}{n} \ln C_{e}
$$

where, $q_{e}$ is the amount of pigment adsorbed at equilibrium $(\mathrm{mg} / \mathrm{g}) ; C_{e}$ is the equilibrium concentration of the adsorbate $(\mathrm{mg} / \mathrm{L}) ; K_{F}(\mathrm{~L} / \mathrm{mg})$ and $n$ are the Freundlich equilibrium coefficients. The value of $n$ gives information on the fa- 
vourability of adsorption process and $K_{F}$ is the adsorption capacity of the adsorbate. Putting $C_{e}$ as $X_{e}$ and $q_{e}$ as $X / m$, Freundlich isotherm takes a new form as shown in Equation (11).

$$
\ln X / m=\ln K_{F}+\frac{1}{n} \ln X_{e}
$$

\subsubsection{Temkin Isotherm}

Temkin and Pyzhev considered the effect of the adsorbate interaction on adsorption and proposed the model known as Temkin isotherm [14]. The linearized form of Temkin isotherm equation is given in Equation (12).

$$
q_{e}=B_{1} \ln K_{T}+B_{1} \ln C_{e}
$$

where, $B_{1}=R T / b, T$ is the absolute temperature in $\mathrm{K}, R$ the universal gas constant, $8.314 \mathrm{~J} \cdot \mathrm{K}^{-1} \cdot \mathrm{mol}^{-1}, K_{T}$ the equilibrium binding constant $(\mathrm{L} / \mathrm{mg})$ and $B_{1}$ is related to the heat of adsorption. Putting $C_{e}$ as $X_{e}$ and $q_{e}$ as $X / m$, Temkin isotherm takes a new form as shown in Equation (13).

$$
X / m=B_{1} \ln K_{T}+B_{1} \ln X_{e}
$$

\subsubsection{Dubinin and Radushkevich Isotherm}

The linear form of Dubinin and Radushkevich (DR) isotherm equation is given in Equation (14) [13].

$$
\ln q_{e}=\ln Q_{m}-\beta \varepsilon^{2}
$$

where, $Q_{m}$ is the D-R monolayer capacity $(\mathrm{mg} / \mathrm{g}), \beta$ is a constant related to adsorption energy, and $\varepsilon$ is the Polanyi potential which is related to the equilibrium concentration as shown in Equation (15).

$$
\varepsilon=R T \ln \left(1+\frac{1}{C_{e}}\right)
$$

where, $R$ is the gas constant $(8.314 \mathrm{~J} / \mathrm{mol} \mathrm{K})$ and $T$ is the absolute temperature. The constant $\beta$ gives the mean free energy, $E$ of adsorption per molecule of the adsorbate when it is transferred to the surface of the solid from infinity in the solution, and can be computed using Equation (16).

$$
E=\frac{1}{\sqrt{2 \beta}}
$$

The isotherm parameters estimated from the isotherm plots with the regression coefficients are listed in Table 4. The results for the four adsorption isotherms indicate that the Temkin isotherm model gave the best fitting for the adsorption data having displayed the highest $R^{2}$ values.

\subsection{Adsorption Thermodynamics}

Thermodynamic parameters, when properly examined could give detailed information regarding the intrinsic energy and structural changes after adsorption. In the practice of environmental engineering, both energy and entropy factors ought to be considered to determine the processes that occur spontaneously 
Table 4. Isotherm parameters for colour pigment removal from palm oil at different temperatures using activated Ibusa clay.

\begin{tabular}{cccccc}
\hline \multirow{2}{*}{ Isotherm models } & Parameters & \multicolumn{4}{c}{ Temperature (K) } \\
\cline { 3 - 6 } & & 343 & 353 & 363 & 373 \\
\hline \multirow{2}{*}{ Freundlich } & $K_{F}(\mathrm{~L} / \mathrm{mg})$ & 0.096 & 0.241 & 0.222 & 0.335 \\
& $R^{2}$ & -0.404 & -1.014 & -1.193 & -2.558 \\
& $K_{a}(\mathrm{~L} / \mathrm{mg})$ & -2.024 & -3.230 & -4.354 & -7.669 \\
Langmuir & $q_{m}(\mathrm{mg} / \mathrm{g})$ & 0.046 & 0.095 & 0.148 & 0.211 \\
& $R^{2}$ & 0.632 & 0.642 & 0.722 & 0.740 \\
Temkin & $K_{T}(\mathrm{~L} / \mathrm{mg})$ & 0.924 & 0.762 & 0.614 & 0.213 \\
& $B_{1}$ & -0.649 & -0.468 & -0.386 & -0.219 \\
& $R^{2}$ & 0.988 & 0.959 & 0.940 & 0.829 \\
& $\beta$ & $-2 \times 10^{-7}$ & $-7 \times 10^{-8}$ & $-4 \times 10^{-8}$ & $-9 \times 10^{-9}$ \\
Dubinin and & $Q_{m}(\mathrm{mg} / \mathrm{g})$ & 0.045 & 0.161 & 0.254 & 0.433 \\
Radushkevich & $R^{2}$ & 0.761 & 0.640 & 0.618 & 0.432 \\
\hline
\end{tabular}

[15]. Thermodynamic parameters, the Gibbs free energy change of adsorption $\Delta G^{o}\left(\mathrm{~kJ} \cdot \mathrm{mol}^{-1}\right)$, enthalpy $\left(\Delta H^{o}\right)$, and entropy $\left(\Delta S^{0}\right)$ for the adsorption of pigments onto activated Ibusa clay were calculated using Equations (17), (19) and (20).

$$
\Delta G^{o}=-R T \ln K_{c}
$$

where $R$ is the universal gas constant $\left(8.314 \times 10^{-3} \mathrm{~J} \cdot \mathrm{mol}^{-1} \cdot \mathrm{K}^{-1}\right), T$ is the absolute temperature and $K_{c}$ is the thermodynamic equilibrium constant. The thermodynamic equilibrium constant $\left(K_{c}\right)$ of the adsorption is defined as shown in Equation (18).

$$
K_{c}=\frac{q_{e}}{C_{e}}
$$

The enthalpy $\left(\Delta H^{D}\right)$ and entropy $\left(\Delta S^{o}\right)$ values are estimated from the substitution of Equation (17) into Equation (19) which gives Equation (20).

$$
\Delta G^{o}=\Delta H^{o}-T \Delta S^{o}
$$

and

$$
\ln K_{c}=\frac{\Delta S^{o}}{R}-\frac{\Delta H^{o}}{R T}
$$

The values of $\Delta G^{o}$ were calculated from Equation (19). The values of $\Delta H^{o}$ and $\Delta S^{o}$ were calculated from the slope and intercept of the plot of $\ln K_{c}$ versus $1 / T$ (not shown). The values of the thermodynamic parameters are shown in Table 5. The negative values of $\Delta G^{o}$ imply that the adsorption of pigments onto acid activated Ibusa was spontaneous. The magnitude of $\Delta G^{o}$ also increased with an increase in the temperature indicating that the adsorption was more favorable at 
Table 5. Thermodynamic parameters for adsorption of pigments onto activated Ibusa clay.

\begin{tabular}{cccc}
\hline Temperature $(\mathrm{K})$ & $\Delta G(\mathrm{~kJ} / \mathrm{mol})$ & $\Delta H(\mathrm{~kJ} / \mathrm{mol})$ & $\Delta S(\mathrm{~J} / \mathrm{mol} \cdot \mathrm{K})$ \\
\hline 343 & -0.500 & 110.39 & 323.33 \\
353 & -3.730 & & \\
363 & -6.970 & & \\
373 & -10.200 & & \\
\hline
\end{tabular}

higher temperatures. The value of $\Delta H^{o}$ was positive, indicating the endothermic nature of the adsorption of pigments onto activated Ibusa clay in the temperature ranges of $343-373 \mathrm{~K}$. The positive value of $\Delta S^{\circ}$ suggested an increase in randomness at the solid/liquid interface during the adsorption.

\section{Conclusion}

Ibusa clay activated with hydrochloric acid has been identified as an efficient adsorbent for the removal of pigments from palm oil, with the removal reaching $97.4 \%$ at $373 \mathrm{~K}$. Kinetic studies reveal that equilibrium was reached within 80 minutes and pseudo-second-order model fitted the experimental data better than other kinetic models. The adsorption isotherms suggest that Temkin isotherm better explained the experimental data for the bleaching of palm oil using activated Ibusa clay than Langmiur, Freundlich and Dubinin-Radushkevich isotherms. The bleaching process was more favourable at higher temperatures, and tends to be endothermic, with increasing randomness at the solid/solution interface.

\section{Conflicts of Interest}

The authors declare no conflicts of interest regarding the publication of this paper.

\section{References}

[1] Okafor, V.N. (2019) Kinetics and Statistical Optimization of Clay Dissolution and Adsorptive Bleaching of Palm Oil. PhD Thesis, Chukwuemeka Odumegwu Ojukwu University, Uli.

[2] Aishat, A.B., Olalekan, S.T., Arinkoola, A.O. and Omolola, J.M. (2015) Effect of Activationon Clay and Carbonaceous Material in Vegetable Oil Bleaching: State of Art Review. British Journal of Applied Science and Technology, 5, 130-141. https://doi.org/10.9734/BJAST/2015/11942

[3] Baranowsky, K., Beyer, W. and Billek, G. (2001) Technologies for Industrial Processing of Fats and Oil. European Journal of Lipid Science and Technology, 103, 505-551. https://doi.org/10.1002/1438-9312(200108)103:8<505::AID-EJLT505>3.0.CO;2-7

[4] Valenzuela, D.F. and De Souza, S.P. (2001) Studies on the Acid Activation of Brazilian Smectiticclays. Quimica Nova, 24, 345-353.

https://doi.org/10.1590/S0100-40422001000300011 
[5] Ajemba, R.O. and Onukwuli, O.D. (2012) Assessing Influence of Hydrochloric Acid Leaching on Structural Changes and Bleaching Performance of Nigerian Clay from Udi. Physicochemical Problems of Mineral Processing, 50, 349-358.

[6] Motlagh, M.M.K., Youzbashi, A.A. and Rigi, Z.A. (2011) Effect of Acid Activation on Structural and Bleaching Properties of a Bentonite. Iranian Journal of Material Science and Engineering, 8, 50-56.

[7] Inglethorpe, S.D.J., Morgan, D.J., Highley, D.E. and Bloodworth, A.J. (1993) Industrial Mineral Laboratory Manual-Bentonite. British Geological Survey Technical Report WG/93/20.

[8] Bakhtyar, K.A., Muhammad, A.A. and Karim, J.J. (2011) Acid Activation and Bleaching Capacity of Some Local Clays for Decolourizing Used Oils. Asian Journal of Chemistry, 23, 113-122.

[9] Engelhard (1996) Raising Performance Standards in Catalysts and Sorbents for Fats and Oils. Engelhard, Houston.

[10] Alver, E. and Metin, A.U. (2012) Anionic Dye Removal from Aqueous Solutions Using Modified Zeolite: Adsorption Kinetics and Isotherm Studies. Chemical Engineering Journal, 200-202, 59-67. https://doi.org/10.1016/j.cej.2012.06.038

[11] Khan, T.A. Dahiya, S. and Ali, I. (2012) Use of Kaolinite as Adsorbent: Equilibrium, Dynamics and Thermodynamic Studies on the Adsorption of Rhodamine B from Aqueous Solution. Applied Clay Science, 69, 58-66. https://doi.org/10.1016/j.clay.2012.09.001

[12] Ajemba, R.O. and Onukwuli, O.D. (2013) Adsorptive Removal of Colour Pigment from Palm Oil Using Activated Nteje Clay: Kinetics, Equilibrium and Thermodynamics. Physicochemical Problems of Mineral Processing, 49, 369 -381.

[13] Rahman, M.M., Akter, N., Karim, M.R., Ahmad, N., Siddiquey, I.A., Bahadur, N.M. and Hasnat, M.A. (2014) Optimization, Kinetic and Thermodynamic Studies for Removal of Brilliant Red (X-3B) Using Tannin Gel. Journal of Environmental Chemical Engineering, 2, 76-83. https://doi.org/10.1016/j.jece.2013.11.023

[14] Auta, M. and Hameed, B.H. (2011) Preparation of Waste Tea Activated Carbon Using Potassium Acetate as an Activating Agent for Adsorption of Acid Blue 25 Dye. Chemical Engineering Journal, 171, 502-509. https://doi.org/10.1016/j.cej.2011.04.017

[15] Ramana, D.K.V., Reddy, D.H.K., Yu, J.S. and Seshaiah, K. (2012) Pigeon Peas Hulls Waste as Potential Adsorbent for Removal of $\mathrm{Pb}(\mathrm{II})$ and $\mathrm{Ni}(\mathrm{II})$ from Water. Chemical Engineering Journal, 197, 24-33. https://doi.org/10.1016/j.cej.2012.04.105 